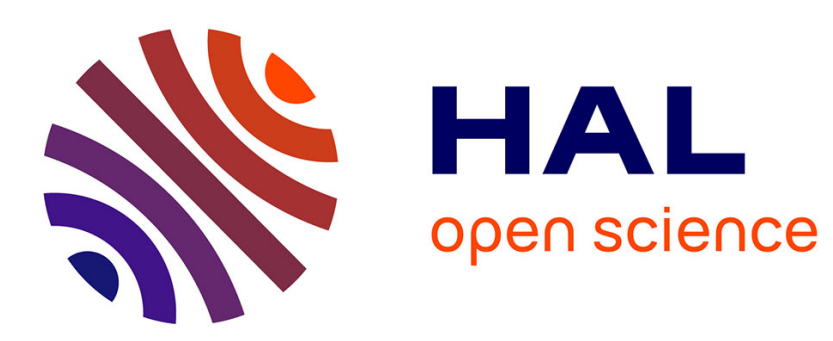

\title{
Impact of HILIC Amino-Based Column Equilibration Conditions on the Analysis of Chitooligosaccharides
}

\author{
Maher Abla, Catherine Ladaviere, Stéphane Trombotto
}

\section{To cite this version:}

Maher Abla, Catherine Ladaviere, Stéphane Trombotto. Impact of HILIC Amino-Based Column Equilibration Conditions on the Analysis of Chitooligosaccharides. Chromatographia, In press, 10.1007/s10337-021-04109-9 . hal-03514674

\section{HAL Id: hal-03514674 \\ https://hal.science/hal-03514674}

Submitted on 6 Jan 2022

HAL is a multi-disciplinary open access archive for the deposit and dissemination of scientific research documents, whether they are published or not. The documents may come from teaching and research institutions in France or abroad, or from public or private research centers.
L'archive ouverte pluridisciplinaire HAL, est destinée au dépôt et à la diffusion de documents scientifiques de niveau recherche, publiés ou non, émanant des établissements d'enseignement et de recherche français ou étrangers, des laboratoires publics ou privés. 


\title{
1 Impact of HILIC amino-based column equilibration conditions on 2 the analysis of chitooligosaccharides
}

3

4

5

\section{Maher Abla, ${ }^{1 *}$ Catherine Ladavière and Stéphane Trombotto}

Ingénierie des Matériaux Polymères, UMR CNRS 5223, Université Claude Bernard Lyon 1, Domaine Scientifique de la Doua, Bâtiment POLYTECH, 15 bd André Latarjet, 69622 Villeurbanne Cedex, France

Catherine.ladaviere@univ-lyon1.fr (C.Ladavière); Stephane.trombotto@univ-lyon1.fr (S.Trombotto)

* Corresponding author Email: maher.abla@ul.edu.lb (M. Abla); phone number: 009613129336; fax number: 009611681552

\begin{abstract}
Obtaining well-defined Chitooligosaccharides (COS) structures is very important as their physicochemical and biological properties depends strongly on their degree of polymerization (DP) and degree of $N$-acetylation (DA). Hydrophilic Interactions Liquid Chromatography (HILIC), that is commonly used for COS analyses, suffers from several drawbacks, related to their complex structure, leading to broadening/splitting of the chromatogram signals. We investigated, herein, on the role of the equilibration step of an amino-based HILIC column on the separation of COS DP $\leq 5$. We demonstrated that COS could be separated according to their DP after equilibrating the column by a $\mathrm{NaHCO}_{3}$ buffer solution $(100 \mathrm{mM}, \mathrm{pH}=10)$ and mild elution chromatographic parameters (neutral mobile phase, r.t.); or according to their DA after equilibrating the column by an $\mathrm{NH}_{4} \mathrm{Ac}$ buffer solution ( $50 \mathrm{mM}, \mathrm{pH}=4.5$ ). Also, the nature of the counterion of the column stationary phase was found to affect both retention times and signal profiles of analyzed COS.
\end{abstract}

Keywords: chitosan, oligomer, HILIC, chromatography, anomer, counter-ion,

\section{Declaration:}

Funding: Bayer CropScience (La Dargoire, France), the University of Lyon, and the Agence Nationale de la Recherche ("BIOCOS" 10-CD2I-008 research project)

Conflict of interest/competing interest: The authors declare no conflict of interest nor competing interest. Availability of data and material: yes (see supporting data file)

Code availability: not applicable

\section{Authors contribution:}

\footnotetext{
${ }^{1}$ Present address: Department of Chemistry and Biochemistry, Laboratoire d'Innovation Thérapeutique (LIT), Lebanese University, Faculty of Sciences II, Fanar, Lebanon.
} 
- Maher ABLA: Methodology/Investigation/Formal analysis/Writing-Original Draft.

- Stéphane Trombotto: Conceptualization/Methodology/Validation/Writing-Review and Editing/ Funding acquisition/ Project administration/Supervision.

- Catherine Ladavière: Conceptualization/Methodology/Validation/Writing-Review and Editing/ Funding acquisition/ Project administration/Supervision.

Ethics approval: not applicable

Consent to participate: not applicable

Consent for publication: not applicable

\section{Introduction.}

ChitoOligoSaccharides (COS) are small oligomers of chitin and chitosan having a degree of polymerization (DP) lower than about 20 units. They are composed of $N$-acetyl-D-glucosamine (GlcNAc) and D-glucosamine (GlcN) repeating units, linked by $\beta$-( $1 \rightarrow 4)$ glycosidic bonds. Two types of COS exist: (i) homo-oligomers that are composed of only GlcN or GlcNAc moieties whereas (ii) hetero-oligomers are composed by a random distribution of both repeating units.[1]

Their water solubility, biodegradability, non-toxicity, and biocompatibility properties explain their many biomedical[2-4] and food applications.[5,6] These COS are known for their multiple bioactivities [7-9] such as antimicrobial, anti-oxidant, anti-inflammatory, anti-tumor, but also as potentially bioactive molecules for the development of biomaterials for skin tissue healing and regeneration.[10] Furthermore, it has been found that COS pentamers, for example, could be used for the preparation of Nodulation factors that are precursors of biological signal molecules with a strong agro-economic impact.[11] Other COS have been prepared as analogues to naturally obtained $N, N, N$-trimethyl-D-glucosaminyl-chitotriomycin, a potentially highly selective natural bactericide, fungicide, and insecticide without any aggressive effect on the environment.[12]

COS are generally prepared by depolymerization of chitin, a highly abundant naturally occurring polysaccharide that can be extracted from either hard-shelled crabs and shrimps or the cell wall of fungi, or from its partially deacetylated derivative called chitosan. Different chemical methods were used for such depolymerizations of chitin and chitosan, for example, acid hydrolysis $[13,14]$ or oxidative degradation.[15,16] Enzymatic depolymerization can also be used for the preparation of COS.[17-19] In order to enhance the efficiency of depolymerization, both chemical and enzymatical methods can sometimes be assisted by ultraviolet,[20] microwave,[21], gamma [22] or ultrasound radiations.[23] However, all these methods of preparation of COS lead in general to mixtures of fully or partially acetylated/deacetylated $\operatorname{COS}$ (i.e., with different degrees of $N$-acetylation (DA) corresponding to the molar ratio of GlcNAc units in the oligomer chain), and different DP. Whereas, the separation of such compounds 
remains challenging, several studies have shown that physicochemical and biological properties of COS are strongly dependent on their DP and DA.[2,24] Therefore, it seems to be crucial to find out novel methods of preparation controlling both DA and DP. To this purpose, two main pathways were investigated: $(i)$ the chemical synthesis of COS starting from GlcN as building block, although this pathway still requires complicated and multisteps synthetic processes which limit the preparation of higher COS or their preparation at gram scale;[25] (ii) the development of robust analytical technical methodologies that could improve the separation or identification of these COS entities according to their DA and/or DP. Several chromatography techniques have been employed for the separation of COS. For instance, size exclusion chromatography,[26] adsorption chromatography,[27] metal affinity chromatography,[28] or ion exchange chromatography.[29] More particularly, hydrophilic interaction liquid chromatography (HILIC) has been widely used for the analysis of highly polar compounds, especially simple and complex carbohydrates.[30-32]. In comparison to other HPLC techniques, HILIC offers several advantages such as: (i) to separate highly polar compounds that cannot be well-retained on reverse phase liquid chromatography (RPLC); (ii) to overcome poor solubility drawbacks of some polar analytes, encountered with normal phase liquid chromatography (NPLC), and finally, (iii) to use no expensive ion pairs reagents as required for ion-exchange chromatography (IC).[33] A large variety of HILIC columns exists and each one has its own mechanism of retention. One of these columns is the amino-based one which results from grafting amino groups onto a silica-based,[34] or a polymeric based stationary phase.[35] The latter one presents many advantages in terms of reproducibility, durability, and high resistance to both alkaline and acidic eluents [36] and has been commonly adopted for COS analysis.[37,38] Despite all the progress accomplished in the analysis of carbohydrates; these biomolecules remain challenging to analyze due to their complex spatial structure and their multiple isomers. The subtle modifications between isomers, mainly in reducing carbohydrates, complicate the analysis and lead sometimes to broadening and splitting of the chromatogram signals. Overcoming such a complication requires using high temperature or high $\mathrm{pH}$ mobile phase. These conditions could reduce the column life. We report herein, the influence of the equilibration conditions of an amino-based HILIC column on the analysis of acetylated and deacetylated $\operatorname{COS}(\mathrm{DP} \leq 5)$ under room temperature and neutral mobile phase acetonitrile/ $\mathrm{H}_{2} \mathrm{O}(7: 3 \mathrm{v} / \mathrm{v})$.

\section{Materials and Methods}

\subsection{Chemicals.}

All deacetylated $\mathrm{COS}$ used were commercially available under their chloride salt form. $(\mathrm{GlcN}) \cdot \mathrm{HCl},(\mathrm{GlcN})_{2} .2 \mathrm{HCl}$, $(\mathrm{GlcNAc})_{1}$, and $(\mathrm{GlcNAc})_{2}$ were purchased from sigma Aldrich Corporation (purity >99\%). $(\mathrm{GlcN})_{3} .3 \mathrm{HCl}$ and 
$(\mathrm{GlcN})_{5} .5 \mathrm{HCl}$ (purity $>98 \%$ ) were purchased from Seigakaku Business Corporation ${ }^{\circledR}$ and characterized by ${ }^{1} \mathrm{H}$ NMR (Supplementary Information Fig S1 and Fig S2). (GlcNAc) 3 (purity >90\%) was purchased from Elicityl. The synthesis of the (GlcNAc) $)_{5}$ and tetra-N-acetylchitopentaose $\left(\mathrm{D}_{1} \mathrm{~A}_{4}\right)$ was carried out following Abla et al.[39] and fully characterized by ${ }^{1} \mathrm{H}$ NMR and MALDI-TOF MS (Supplementary Information Fig S3-S5). Water was obtained from a Milli-Q Water Purification. All commercially chemicals and solvents were used directly without any further purification.

\subsection{Chromatography analyses and sample preparation}

The chromatographic analysis was performed on a Shimadzu HPLC Model CBM-20A equipped with a shodex Asahipak NH2P-50 4E column (5 $\mu \mathrm{m}$ granulometry, $250 \mathrm{~mm} \times 4.6 \mathrm{~mm}$ ), a shodex Asahipak NH2P-50G 4A guard column and Shimadzu RID-10A detector. The mobile phase was composed of a mixture of acetonitrile/ $\mathrm{H}_{2} \mathrm{O}(7: 3$ $\mathrm{v} / \mathrm{v}$ ). The stationary phase was equilibrated by eluting the adequate $\mathrm{pH}$ solution under a constant flow rate of 0.2 $\mathrm{mL} / \mathrm{min}$ for a period of 72 hours. Then the mobile phase $\left(\mathrm{ACN} / \mathrm{H}_{2} \mathrm{O} 7: 3 \mathrm{v} / \mathrm{v}\right)$ was eluted at a flow rate of 0.8 $\mathrm{mL} / \mathrm{min}$ for two hours before injections. All COS samples were prepared in a similar way, by dissolving the accurate amount of the solid in a mixture of acetonitrile/ $\mathrm{H}_{2} \mathrm{O}(1: 1 \mathrm{v} / \mathrm{v})$ at $25 \mathrm{mg} / \mathrm{mL}$ and injected $(10 \mu \mathrm{L})$ at room temperature, at a constant flow rate of $0.8 \mathrm{~mL} / \mathrm{min}$.

To assess the repeatability of the chromatography analysis, relative standard deviation (RSD) values were calculated for all the samples and under different chromatography conditions. It is worthy to note that the measurements were performed on 5 different measurements for each oligomer samples and these measurements were performed on several days. The RSD obtained are presented in Table 1 and were satisfactory $(<5 \%)$. (Supplementary Information Table S1-S3)

\section{Results and Discussion.}

Despite a very complex retention mechanism of HILIC, it is mainly considered as a hydrophilic partitioning between a highly organic rich mobile phase and a semi-immobilized water enriched layer neighboring to the stationary phase.[33,40,41] HILIC systems possess a diversity of stationary phases (neutral or ionic) onto which a variety of ligands could be attached, and several types of mobile phases could also be used. Therefore, in order to better understand the retention mechanism of analytes, other types of interactions such as hydrogen bonds, dipoledipole, or ionic attractive or repulsive interactions should also be taken into consideration.[33,40] The shodex Asahipak NH2P column used in this study is an amino-based stationary phase composed of polyvinyl alcohol 
hydrophilic polymer onto which secondary ethyl-amino groups are grafted.[36] Thus the ratio of protonated/unprotonated amino groups of the stationary phase highly depends on the $\mathrm{pH}$ of the solution used to equilibrate the column, as well as the $\mathrm{pH}$ of the eluent, if this latter is different. This ratio could have a great influence on the interactions between the stationary phase and the analytes, therefore, the separation of COS should take into consideration four main experimental parameters: (i) the nature and the $\mathrm{pH}$ of the solution used to equilibrate the stationary phase; (ii) the amphoteric character of the secondary amino groups ( $\mathrm{pKa}=10$, data given by the supplier) of the stationary phase; (iii) the cationic or neutral form of the COS (intrinsic dissociation constant for fully deacetylated $\mathrm{COS}_{\mathrm{pK}} \sim 6.5-7.5$; [42] and finally, (iv) the $\mathrm{pH}$ of the eluent. In order to ensure that analytes will remain in their initial form as they were injected, a neutral mobile phase composed of a mixture of acetonitrile and water $(7: 3 ; \mathrm{v} / \mathrm{v})$ was used in all the experiments. For the sake of clarity in this work, COS were abbreviated as $D_{x} A_{y}$ Fig 1 as it was previously published[43] where "x" and " $y$ " are the number of deacetylated $(D=G l c N)$ and acetylated $(\mathrm{A}=\mathrm{GlcNAc})$ units, respectively.

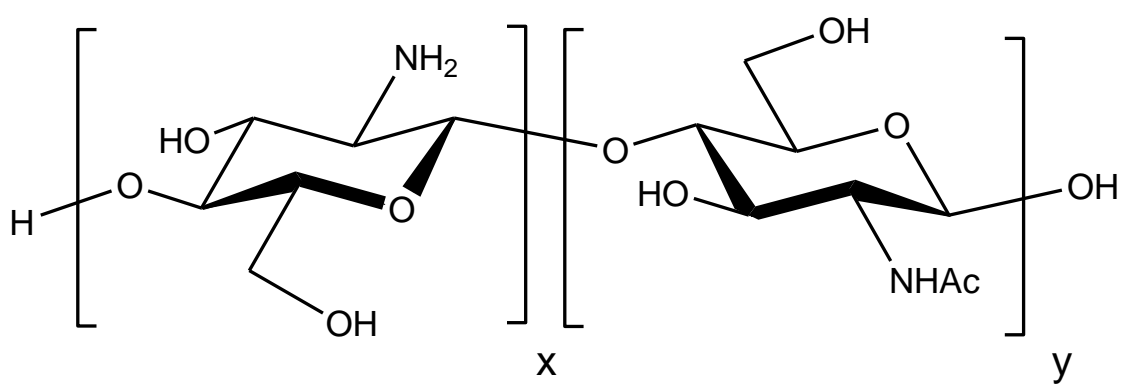

GlcN (or D)

GlcNAc (or A)

Fig 1 Chemical structure of $\operatorname{COS}\left(D_{x} A_{y}\right.$ with $\left.D P=x+y \leq 5\right)$ studied in this work.

\subsection{Column equilibration under acidic conditions}

First, the stationary phase was equilibrated, with a continuous flow of an $\mathrm{H}_{2} \mathrm{SO}_{4}$ solution $(50 \mathrm{mM} ; \mathrm{pH}=1)$. Under these conditions, the secondary amino groups of the stationary phase were converted into their ammonium sulfate form. Then, different COS with well-defined DP, ranging from 1 to 5 , fully acetylated $\left(D_{0} A_{y}\right)$, fully deacetylated $\left(D_{x} A_{0}\right)$ or partially acetylated $\left(D_{1} A_{4}\right)$ were analyzed and the results are summarized in Table 1.

Table 1 Summary of the HILIC analyses of different fully acetylated $\left(D_{0} A_{x}\right)$, fully deacetylated $\left(D_{x} A_{0}\right)$ and partially acetylated $\left(\mathrm{D}_{1} \mathrm{~A}_{4}\right) \mathrm{COS}$ : (a) $\mathrm{pH}$ of the solution used for the equilibration of the column; (b) retention time (in min); (c) standard deviation (in min); Relative standard deviation (in \%) were calculated and found $<5 \%$. 


\begin{tabular}{|c|c|c|c|c|c|c|c|c|c|c|c|c|c|}
\hline \multirow[t]{2}{*}{$\mathbf{p H ^ { ( a ) }}$} & & \multirow[t]{2}{*}{$\mathbf{D}_{1} \mathbf{A}_{0}$} & \multirow[t]{2}{*}{$\mathbf{D}_{3} \mathbf{A}_{0}$} & \multirow[t]{2}{*}{$\mathrm{D}_{5} \mathrm{~A}_{0}$} & \multicolumn{2}{|c|}{$\mathbf{D}_{0} \mathbf{A}_{1}$} & \multicolumn{2}{|c|}{$\mathrm{D}_{0} \mathrm{~A}_{2}$} & \multicolumn{2}{|c|}{$\mathbf{D}_{0} \mathbf{A}_{3}$} & \multicolumn{2}{|c|}{$\mathrm{D}_{0} \mathbf{A}_{5}$} & \multirow[t]{2}{*}{$\mathrm{D}_{1} \mathrm{~A}_{4}$} \\
\hline & & & & & $\alpha$ & $\beta$ & $\alpha$ & $\beta$ & $\alpha$ & $\beta$ & $\alpha$ & $\beta$ & \\
\hline \multirow{2}{*}{1} & $t_{R}{ }^{(b)}$ & - & - & - & 7.3 & 8.7 & 8.8 & 10.5 & 12.0 & 14.5 & 21.8 & 26.6 & - \\
\hline & $\mathrm{SD}^{(c)}$ & - & - & - & 0.1 & 0.3 & 0.3 & 0.4 & 0.3 & 0.4 & 0.1 & 0.3 & - \\
\hline \multirow{2}{*}{4.5} & $t_{R}^{(b)}$ & - & - & 7.3 & \multicolumn{2}{|c|}{7.5} & \multicolumn{2}{|c|}{8.7} & \multicolumn{2}{|c|}{10.5} & \multicolumn{2}{|c|}{16.8} & 10.6 \\
\hline & $\mathrm{SD}^{(c)}$ & - & - & 0.2 & \multicolumn{2}{|c|}{0.3} & \multicolumn{2}{|c|}{0.3} & \multicolumn{2}{|c|}{0.6} & \multicolumn{2}{|c|}{0.1} & 0.1 \\
\hline \multirow[b]{2}{*}{10} & $t_{R}^{(b)}$ & 7.6 & 9.6 & 13.3 & \multicolumn{2}{|c|}{7.1} & \multicolumn{2}{|c|}{8.1} & \multicolumn{2}{|c|}{9.9} & \multicolumn{2}{|c|}{13.6} & 14.0 \\
\hline & $\mathrm{SD}^{(c)}$ & 0.2 & 0.2 & 0.4 & \multicolumn{2}{|c|}{0.3} & \multicolumn{2}{|c|}{0.3} & \multicolumn{2}{|c|}{0.5} & \multicolumn{2}{|c|}{0.5} & 0.6 \\
\hline
\end{tabular}

150

These experiments showed that fully deacetylated $\operatorname{COS}\left(D_{x} A_{0}\right)$, injected in their chloride salt form, were not retained by the column (Supplementary Information Fig S6), likely as a consequence of electrostatic repulsions with the cationic stationary phase. On the other hand, a better retention was observed when fully acetylated COS $\left(\mathrm{D}_{0} \mathrm{~A}_{\mathrm{y}}\right)$ were analyzed Fig 2.

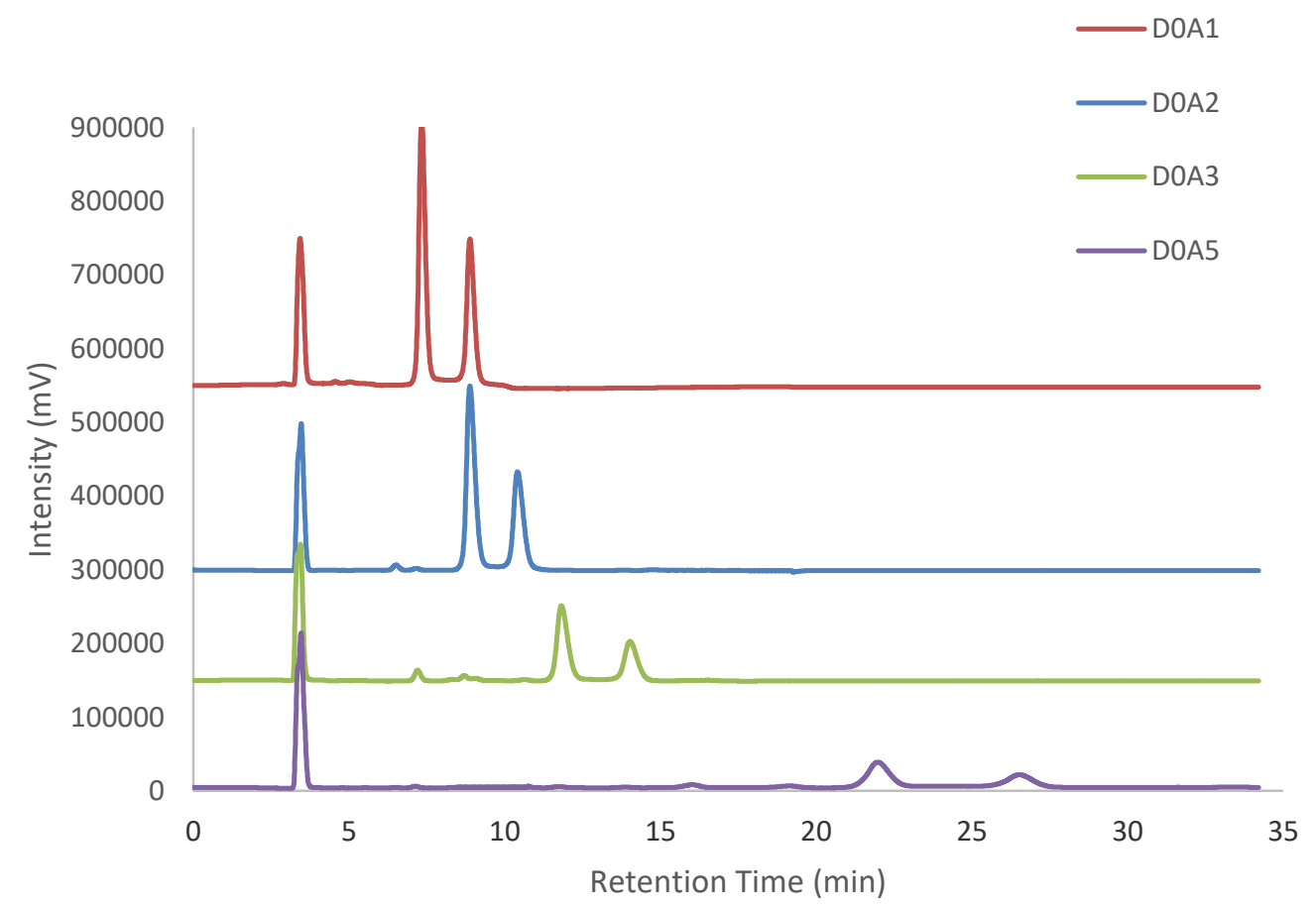

Fig 2 Chromatograms of fully acetylated $\operatorname{COS}\left(\mathrm{D}_{0} \mathrm{~A}_{\mathrm{y}}\right.$ with $\mathrm{y}=1,2,3$ or 5$)$ after equilibrating the column stationary phase by a sulfuric acid solution $(50 \mathrm{mM}, \mathrm{pH}=1)$.

In this case, the retention of these neutral COS to the cationic stationary phase was likely controlled through hydrophilic interactions.[40] Following this assumption, it was obvious to note that the retention time increased with the number of repeating units as the hydrophilic interactions are stronger with higher DP COS. Besides, the signal of each fully acetylated $\operatorname{COS}\left(\mathrm{D}_{0} \mathrm{~A}_{\mathrm{y}}\right)$ was split into two peaks Fig 2 . This observation, in agreement with the literature,[44-46] is a consequence of the mutarotation phenomenon. The interconversion between $\alpha$ and $\beta$ anomers is commonly observed when analyzing reducing sugars on HILIC and appears when the anomerism rate 
is sufficiently low to permit the resolution of the two anomers.[47] However, in order to confirm experimentally this assumption, a sample of $\mathrm{D}_{0} \mathrm{~A}_{1}$ was injected under the same chromatographic conditions and a portion of the ascending slope of its first peak was separated. This latter portion was then injected in a different run and showed again two separated peaks having the same integration ratio and same retention times as for the two peaks of the former sample injection (Supplementary Information Fig S7 and Table S4). It is worthy to note, that for all COS analyzed in this study, $\alpha$ anomers showed shorter retention times than $\beta$ isomers indicating a weaker interaction of $\alpha$ anomers with the stationary phase. For each COS, the anomer/peak assignment was based on the peak area integration ratio of 2:1 assigned for $\alpha$ : $\beta$ anomers, respectively, as found in the literature for D-glucosamine, $[48,49]$ which is also in agreement with the $\alpha$ : $\beta$ peak integration ratio calculated from ${ }^{1} \mathrm{H}$ NMR spectra of fully acetylated and deacetylated COS (Supplementary Information Fig S1-S3).

175

The mutarotation phenomenon limits the use of HILIC systems regarding the quantitative and qualitative analysis of reducing carbohydrates. In order to overcome such a problem, chemical modifications of the carbohydrate analytes are proposed by some authors.[50] However, these methods are not suitable for preparative chromatography separation. In order to avoid the separation of anomer peaks, it is usually recommended to work at high temperature $\left(\right.$ e.g., above $\left.45^{\circ} \mathrm{C}\right)$ where the mutarotation rate becomes much faster than the timescale for chromatography separation.[34,51] Another way to make the two anomer peaks collapse is by adding some additives to the mobile phase. For instance, the addition of tertiary amines (e.g. TEA) was found to suppress the split of the two anomer peaks of reducing monosaccharides and small oligosaccharides.[47] The rate constant of the mutarotation could also be improved by raising the $\mathrm{pH}$ of the mobile phase.[52,53]

Kahle et al.[54] have shown that converting an amino-based silica gel column into sulfate or phosphate forms (strong kosmotropic ions) led to anomers separation whereas after converting it to perchlorate form (strong chaotropic ion) the two anomer peaks collapsed. Kosmotropic ions are known for their strong hydrogen bonds with water molecules which leads to an increase in water viscosity, while chaotropic ions act oppositely.[55] Accordingly, we intended to replace the sulfate ion by a less kosmotropic ion, for instance an acetate ion, by equilibrating the stationary phase with an ammonium acetate buffer solution $(50 \mathrm{mM}, \mathrm{pH}=4.5)$. Due to its relatively high solubility in acetonitrile, its volatility and compatibility with other techniques such as mass spectrometry, the ammonium acetate salt is typically used in HILIC studies.[40,56] As a result, fully deacetylated $\operatorname{COS}\left(D_{x} A_{0}\right)$ were not well retained while fully acetylated $\operatorname{COS}\left(D_{0} A_{y}\right)$ were successfully well separated according to their DP with a $R_{s} \geq 1.2$ Table 2, and were eluted in one single peak Fig 3. In addition, we noted that, for a given single COS, the retention time in presence of acetate ions was shorter than in presence of sulfate ions. For instance, 

of sulfate ions Table 1 .

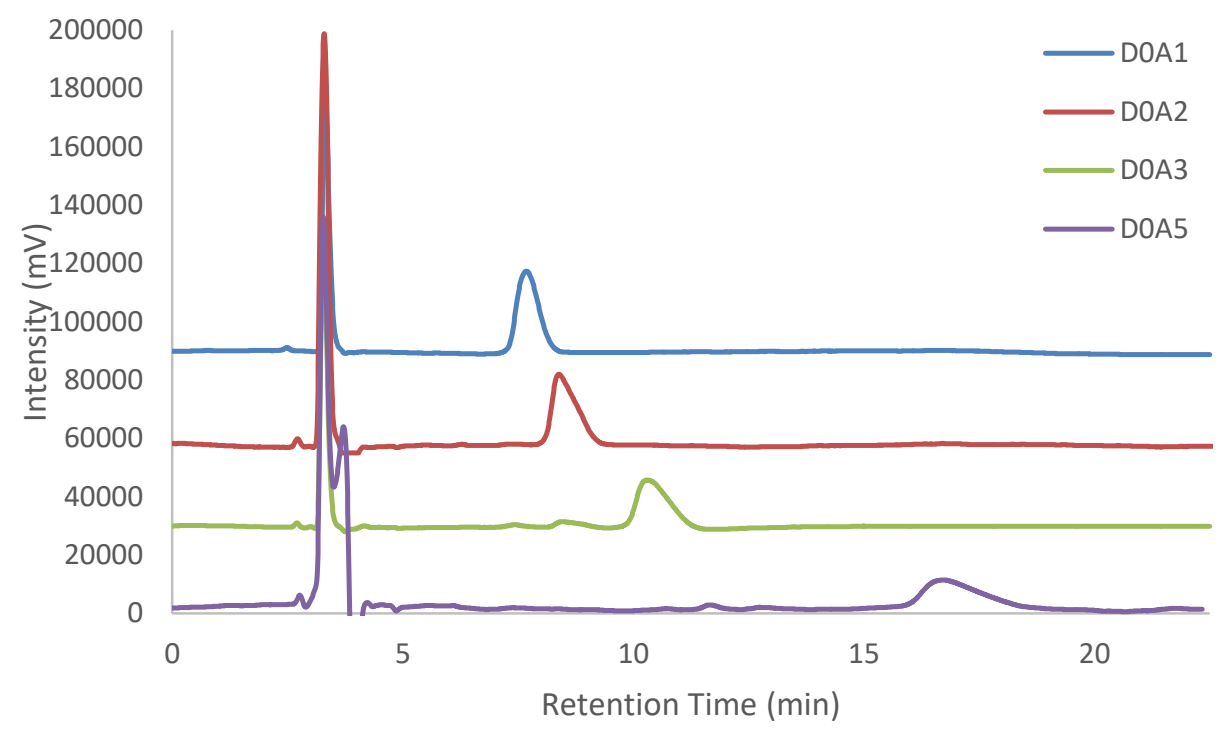

Fig 3 Chromatograms of fully acetylated $\operatorname{COS}\left(\mathrm{D}_{0} \mathrm{~A}_{\mathrm{y}}\right.$ with $\mathrm{y}=1,2,3$ or 5$)$ after equilibrating the column stationary phase by an ammonium acetate buffer solution $(50 \mathrm{mM}, \mathrm{pH}=4.5)$.

Table 2 Selectivity $(\alpha)$ and peak resolutions $\left(R_{s}\right)$ between different COS pairs; retention times of $D_{0} A_{4}, D_{2} A_{0}$ and $D_{4} A_{0}$ were theoretically calculated from the standard curves of their corresponding $D_{x} A_{y}$ series $\left(r^{2}>0.9980\right)$ in order to calculate their selectivity and peak resolution (see Supplementary Information).

\begin{tabular}{|c|c|c|c|c|}
\hline \multirow{2}{*}{ COS pairs } & \multicolumn{2}{|c|}{ pH 4.5} & \multicolumn{2}{|c|}{ pH 10} \\
\hline & $\alpha$ & $\mathbf{R}_{\text {s }}$ & $\alpha$ & $\mathbf{R}_{\mathrm{s}}$ \\
\hline $\mathbf{D}_{1} \mathbf{A}_{0} / \mathbf{D}_{2} \mathbf{A}_{0}$ & - & - & 1.2 & 1.8 \\
\hline $\mathbf{D}_{2} \mathbf{A}_{0} / \mathbf{D}_{3} \mathbf{A}_{0}$ & - & - & 1.2 & 2.3 \\
\hline $\mathbf{D}_{3} \mathbf{A}_{0} / \mathbf{D}_{4} \mathbf{A}_{0}$ & - & - & 1.3 & 2.8 \\
\hline $\mathbf{D}_{4} \mathbf{A}_{0} / \mathbf{D}_{5} \mathbf{A}_{0}$ & - & - & 1.3 & 2.9 \\
\hline $\mathbf{D}_{0} \mathbf{A}_{1} / \mathbf{D}_{0} \mathbf{A}_{2}$ & 1.3 & 1.2 & 1.3 & 1.8 \\
\hline $\mathbf{D}_{0} \mathbf{A}_{2} / \mathbf{D}_{0} \mathbf{A}_{3}$ & 1.3 & 1.5 & 1.4 & 2.6 \\
\hline $\mathbf{D}_{0} \mathbf{A}_{3} / \mathbf{D}_{0} \mathbf{A}_{4}$ & 1.4 & 1.9 & 1.3 & 2.1 \\
\hline $\mathrm{D}_{0} \mathrm{~A}_{4} / \mathrm{D}_{0} \mathrm{~A}_{5}$ & 1.4 & 1.9 & 1.2 & 2.2 \\
\hline $\mathbf{D}_{5} \mathbf{A}_{0} / \mathbf{D}_{1} \mathbf{A}_{4}$ & 1.8 & 2.5 & 1.1 & 0.5 \\
\hline $\mathrm{D}_{1} \mathbf{A}_{4} / \mathrm{D}_{0} \mathrm{~A}_{5}$ & 1.9 & 3.4 & 1.0 & 0.2 \\
\hline $\mathbf{D}_{1} \mathbf{A}_{0} / \mathbf{D}_{0} \mathbf{A}_{1}$ & - & - & 1.1 & 1.1 \\
\hline $\mathbf{D}_{3} \mathbf{A}_{0} / \mathbf{D}_{0} \mathbf{A}_{3}$ & - & - & 1.1 & 0.5 \\
\hline $\mathbf{D}_{5} \mathbf{A}_{0} / \mathbf{D}_{0} \mathbf{A}_{5}$ & 3.4 & 5.2 & 1.0 & 0.4 \\
\hline
\end{tabular}

The difference between the two counter ions, regarding both the signal profile and the retention time, could be related to their degree of hydration as it is already described in the literature. Indeed, several studies [56-58] have demonstrated that the presence of salts promotes the retention of ionic and nonionic analytes. The common explanation suggests that, the presence of solvated salt ions in the water-enriched layer, increases its thickness. 
Thus, the partitioning of polar analytes into this layer is reinforced and the analyte-ligand interactions, for instance hydrogen bonds, are strengthened. This would increase the retention time.[58] The thickness of the water-enriched layer adjacent to the stationary phase plays, therefore, an important role in the modulation of the retention characteristics.[59] Alpert et al.,[57] showed that the nature of the counter ion has an influence on the thickness of the water-enriched layer. They have demonstrated that a highly hydrated kosmotropic ions such as sulfates have markedly promoted the retention time, and a weakly hydrated chaotropic ions, for instance perchlorate ions, had opposite effects. A similar trend was also observed by Bicker et al.[58] by comparing the influence of a more hydrated ions (e.g. acetate ions) to less hydrated ions (e.g. trifluoroacetate ions) on the retention times under HILIC separations. These results are in good agreement with our observations and would suggest that as the degree of hydration of sulfates ions (strong kosmotropic ions) is higher than the acetates ions (weak kosmotropic ions), the water-enriched layer containing the former ions should be thicker than the one with the latter ions. This would be a suitable hypothesis to explain the higher retention times of COS obtained in presence of sulfate ions as compared to acetate ions Table 1. Concerning the signal profile and the anomeric separation, one could hypothesize that in the more viscous water-enriched layer containing sulfate ions, the mutarotation rate would be slower than in presence of acetate ions, which results in the separation of the two anomers. This reminds the results obtained by Kahle et al.[54] up mentioned and comparing the effect of counter ions of the stationary phase on the anomeric separation. Our results showed that the anomers resolution is affected by the nature of the counter ion of the stationary phase even when using a neutral mobile phase.

Finally, another feature of the presence of the acetate counter ions in proximity of the stationary phase exist in the behavior of the fully deacetylated $\operatorname{COS} \mathrm{D}_{5} \mathrm{~A}_{0}$ in its chloride form. Indeed, under these conditions, the $\operatorname{COS} \mathrm{D}_{5} \mathrm{~A}_{0}$ was weakly retained $\left(t_{R}=7.3 \mathrm{~min}\right)$ as if the electrostatic repulsions are weaker than in the case of sulfate ions. This result is very interesting as it allows the separation of COS according their DA. Indeed, Fig 4-a show a large difference in retention times between COS pentamers with different $\mathrm{DA}$, i.e. $\mathrm{D}_{5} \mathrm{~A}_{0}, \mathrm{D}_{1} \mathrm{~A}_{4}$ and $\mathrm{D}_{0} \mathrm{~A}_{5}$ (7.3 min, 10.6 min and $16.8 \mathrm{~min}$, respectively) even when the three COS were injected together (Fig. 4-b). The calculation of $\mathrm{R}_{\mathrm{S}}$ for these three COS pentamers (ranging between 2.5 and 5.2, table 2) confirms their perfect separation under these conditions. In order to confirm the efficiency of the separation according to the DA, we carried out the selective tetra $\mathrm{N}$-acetylation of the commercially available $\mathrm{D}_{5} \mathrm{~A}_{0}$ according to the method previously described by Abla $e t$ al.[39] Following this method, two acetylated derivatives of the pentamer starting material were obtained and (50 mM, pH=4.5) Fig 4-c. 
a)

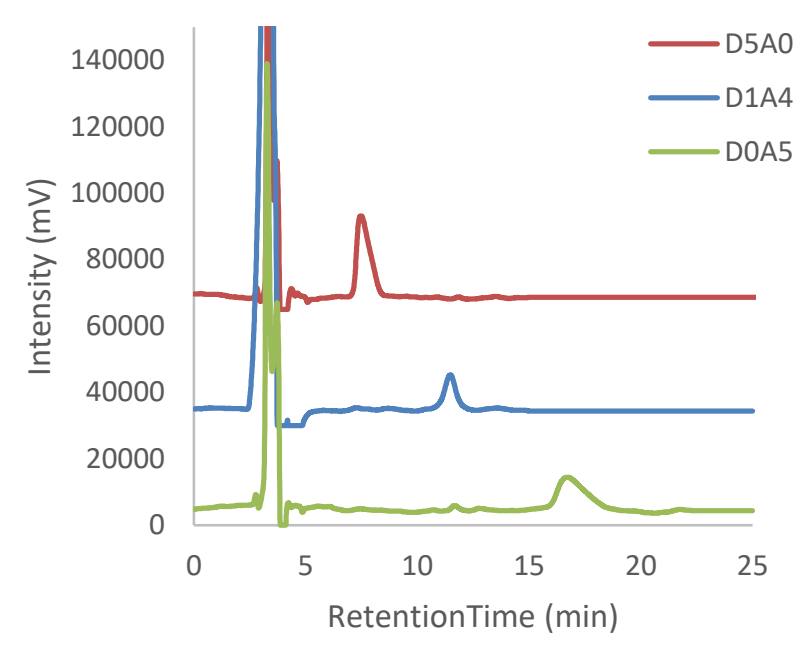

b)

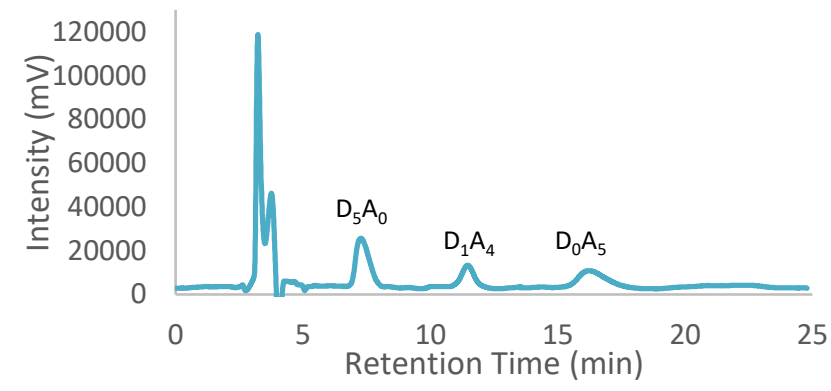

c)

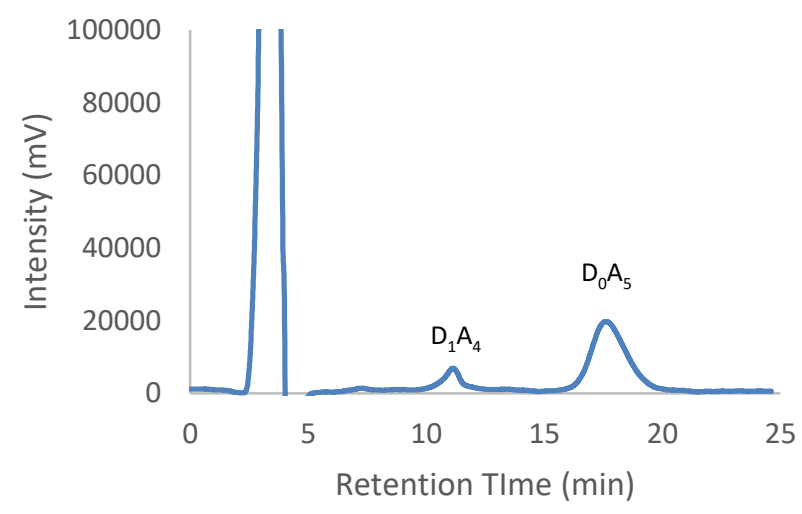

Fig 4 Analyses of three COS pentamers $\left(D_{5} A_{0}, D_{0} A_{5}\right.$ and $\left.D_{1} A_{4}\right)$ after equilibrating the column stationary phase by an ammonium acetate buffer solution (50 mM, $\mathrm{pH}=4.5)$ : a) chromatogram of the three pure COS pentamers; b) chromatogram of a mixture composed of the three COS pentamers; c) chromatogram of a mixture composed of $\mathrm{D}_{1} \mathrm{~A}_{4}$ and $\mathrm{D}_{0} \mathrm{~A}_{5}$ obtained after the $N$-acetylation of $\mathrm{D}_{5} \mathrm{~A}_{0}$ described by Abla et al.[39]

\subsection{Column equilibration under alkaline conditions}

254 In order to decrease the repulsive electrostatic interactions, and to improve the retention of fully deacetylated COS 
bicarbonate $(100 \mathrm{mM}, \mathrm{pH}=10)$. After that, two series of fully deacetylated $\operatorname{COS}\left(\mathrm{D}_{\mathrm{x}} \mathrm{A}_{0}\right.$ in their hydrochloride form) and fully acetylated $\operatorname{COS}\left(\mathrm{D}_{0} \mathrm{~A}_{\mathrm{y}}\right)$ were injected. The results, shown in Fig 5 and Fig 6 for $\mathrm{D}_{0} \mathrm{~A}_{\mathrm{y}}$ and $\mathrm{D}_{\mathrm{x}} \mathrm{A}_{0}$, respectively and summarized in Table1, demonstrated a good affinity of both types of COS to the stationary phase. In both series, a very satisfactory peak resolution $\left(R_{s}\right)$ was observed $\left(R_{s} \geq 1.8\right.$, Table 2$)$ and the retention time highly depended on the DP. The Rs values are higher than in the case of ammonium acetate equilibration $(50 \mathrm{mM}$, $\mathrm{pH}=4.5)$. As it could be expected, no splitting of the peaks was observed.

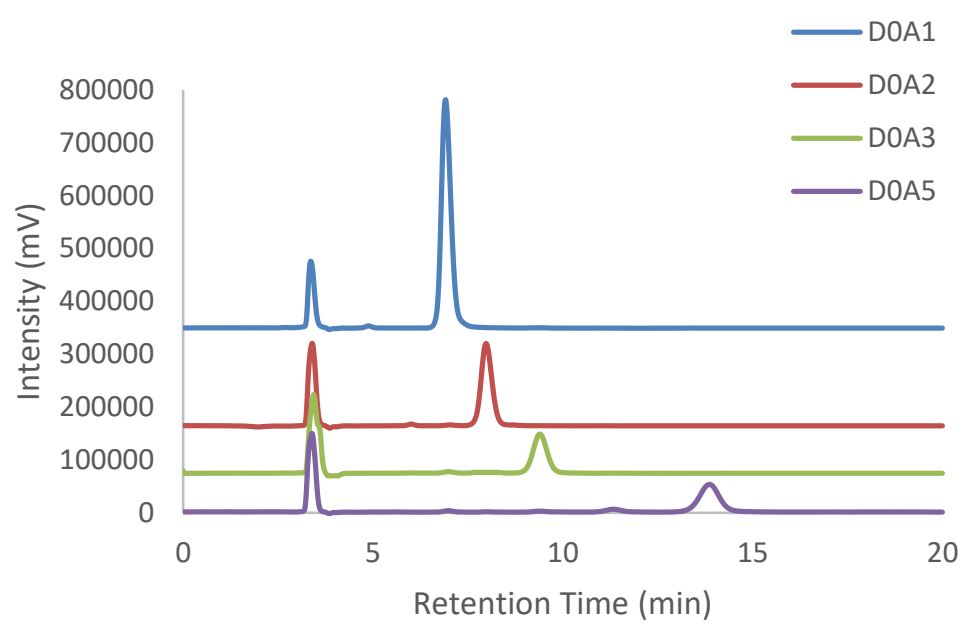

262

Fig 5 Chromatograms of fully acetylated $\operatorname{COS}\left(\mathrm{D}_{0} \mathrm{~A}_{\mathrm{y}}\right.$ with $\mathrm{y}=1,2,3$ or 5$)$ after equilibrating the column stationary phase by a sodium bicarbonate buffer solution $(100 \mathrm{mM}, \mathrm{pH}=10)$.

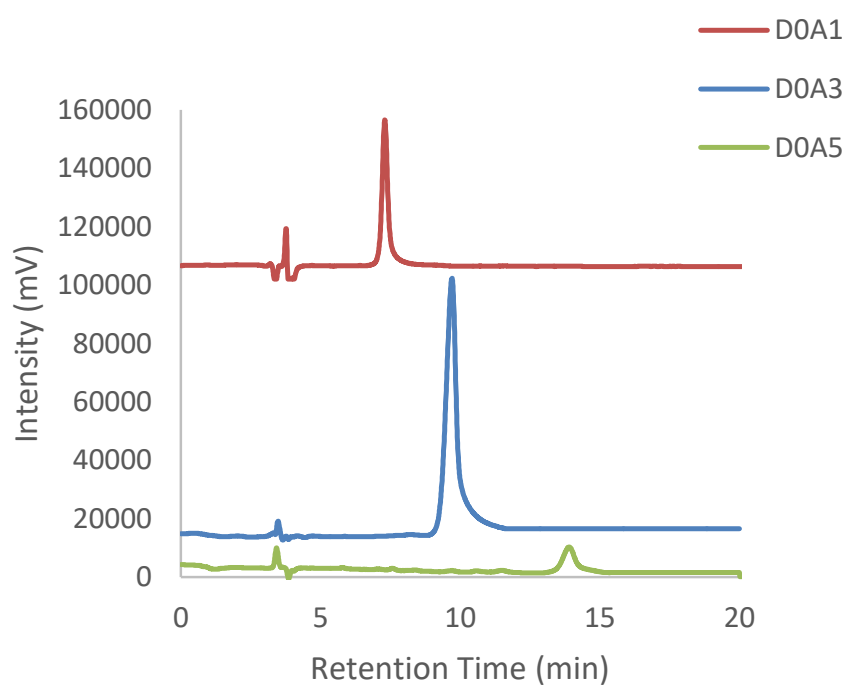

Fig 6 Chromatograms of fully deacetylated $\operatorname{COS}\left(D_{x} A_{0}\right.$ with $x=1,3$ or 5$)$ after equilibrating the column stationary phase by a sodium bicarbonate buffer solution $(100 \mathrm{mM}, \mathrm{pH}=10)$.

However, the retention times of fully acetylated $\left(D_{0} A_{y}\right)$ and deacetylated $\left(D_{x} A_{0}\right) \operatorname{COS}$ having the same DP were very close in contrast to the equilibration with the ammonium acetate buffer, for instance, $7.1 \mathrm{~min}$ and $7.5 \mathrm{~min}$, 

weak resolution $\left(\mathrm{R}_{\mathrm{s}}=1.1\right.$, Table 2$)$; the same tendency was also observed with three COS pentamers differing by their DA. Indeed, very close $t_{R}$ values of $13.3 \mathrm{~min}, 13.6 \mathrm{~min}$ and $14.0 \mathrm{~min}$, were found for $\mathrm{D}_{5} \mathrm{~A}_{0}, \mathrm{D}_{0} \mathrm{~A}_{5}$ and $\mathrm{D}_{1} \mathrm{~A}_{4}$, respectively and $R_{s}$ values were $\leq 0.5$ Fig 8 and Table 2 . These results show the efficiency of an alkaline equilibration on the separation of COS according to their DP but not their DA.

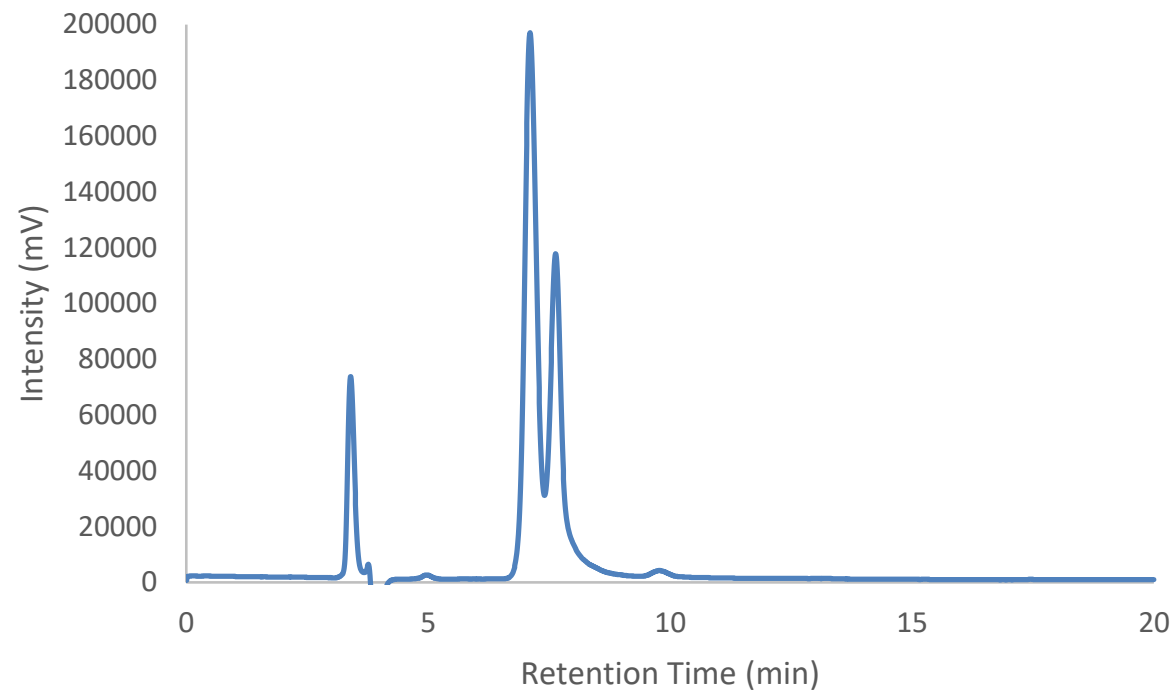

277

Fig 7 Chromatogram of a mixture of $\operatorname{COS}$ monomers $\left(\mathrm{D}_{1} \mathrm{~A}_{0}\right.$ and $\mathrm{D}_{0} \mathrm{~A}_{1}$; mass ratio $\mathrm{D}_{1} \mathrm{~A}_{0}: \mathrm{D}_{0} \mathrm{~A}_{1}$ 2:3) after equilibrating the column stationary phase by a sodium bicarbonate buffer solution $(100 \mathrm{mM}, \mathrm{pH}=10)$.

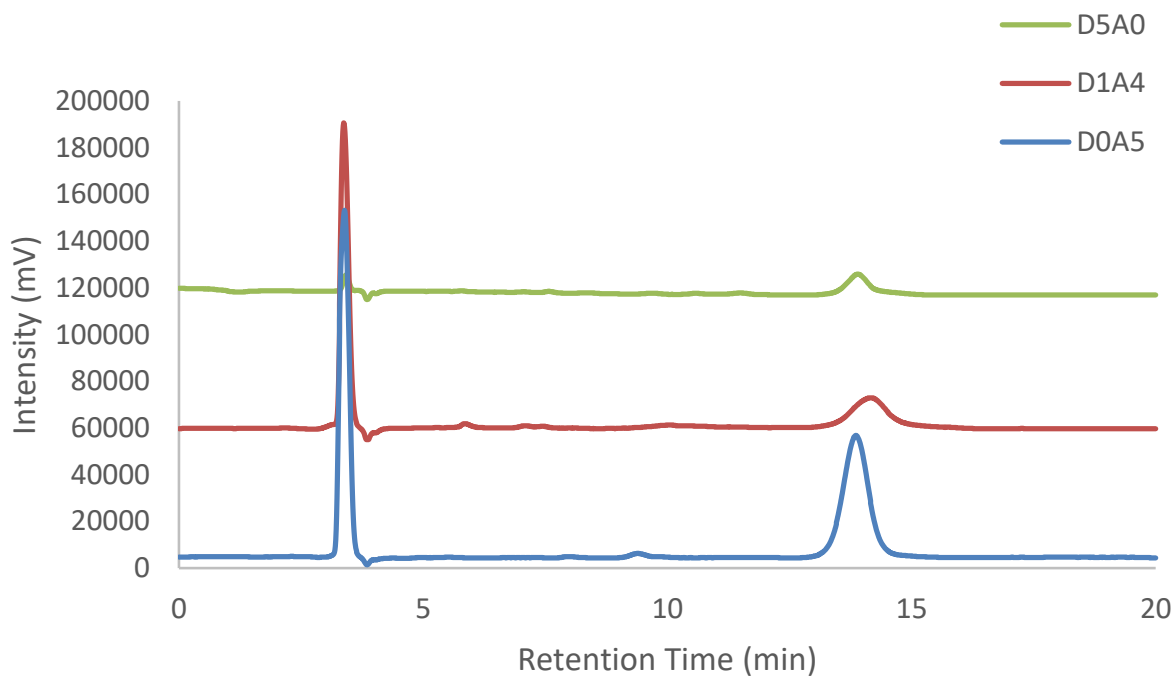

Fig 8 Chromatograms of three COS pentamers $\left(D_{5} A_{0}, D_{0} A_{5}\right.$ and $\left.D_{1} A_{4}\right)$ after equilibrating the column stationary phase by a sodium bicarbonate buffer solution $(100 \mathrm{mM}, \mathrm{pH}=10)$. 


\section{Conclusion.}

In this study, the effect of both the $\mathrm{pH}$ and the nature of the salt of the solution used for equilibrating the aminobased stationary phase of HILIC column was investigated. The results showed that a high pH equilibrating solution, for instance a sodium bicarbonate buffer solution $(100 \mathrm{mM}, \mathrm{pH}=10)$, is the most appropriate for both completely acetylated and deacetylated $\mathrm{COS}$ analysis $\left(\mathrm{R}_{\mathrm{s}}\right.$ values $\left.\geq 1.8\right)$ using $\mathrm{ACN} / \mathrm{H}_{2} \mathrm{O}(7: 3 \mathrm{v} / \mathrm{v})$ as mobile phase. Indeed, the retention times as well as the separation of these oligomers were DP dependent. Although the resolution of anomers is considered as a major limitation concerning the analysis of carbohydrates (mainly when it comes to preparative HPLC analysis of reducing carbohydrates), we showed that the choice of the counter ion (e.g., acetate or sulfate) of ammonium groups of the column stationary phase is crucial. For instance, sulfate ions favor the separation of anomers, while the presence of acetate ones favors the merging of the two anomer peaks and leads to lower retention times. Whereas other published methods preconize the use of high $\mathrm{pH}$ mobile phases to merge the anomer peaks, which could affect the state of the analytes and therefore complicate the analysis, our method should be considered to be interesting in terms of simplifying the chromatographic conditions of COS analysis. It permits to overcome the anomerization drawbacks while working under room temperature and neutral mobile phase. We hypothesized that the degree of hydration of the counter ion of ammonium groups of the column stationary phase would affect the thickness of the immobilized water-enriched layer which in turn would influence the retention time as well as the interaction between the analytes and the column stationary phase ligands. In addition, the results obtained in this study showed that equilibrating the stationary phase by an ammonium acetate buffer solution $(50 \mathrm{mM}, \mathrm{pH}=4.5)$ could be used for the separation of COS according to their DA. This latter result was demonstrated in this work with $\operatorname{COS}$ pentamers $(\mathrm{Rs} \geq 2.5)$ and likely requires further investigations for COS with other DP.

\section{Acknowledgments}

Financial support from Bayer CropScience (La Dargoire, France), the University of Lyon, and the Agence Nationale de la Recherche ("BIOCOS" 10-CD2I-008 research project) are greatly acknowledged. We also thank Mrs. Agnès Crépet for her technical help in HILIC analyses.

\section{References}

[1] Liaqat, F., Eltem, R. 2018. Chitooligosaccharides and their biological activities: A comprehensive review. Carbohydrate Polymers. 184:243-259. 
[2] Xia, W., Liu, P., Zhang, J., Chen, J. 2011. Biological activities of chitosan and chitooligosaccharides. Food Hydrocolloids. 25:170-179.

[3] Phil, L., Naveed, M., Mohammad, I. S., Bo, L., Bin, D. 2018. Chitooligosaccharide: An evaluation of physicochemical and biological properties with the proposition for determination of thermal degradation products. Biomedicine \& Pharmacotherapy. 102:438-451.

[4] Huang, X., Jiao, Y., Zhou, C. 2021. Impacts of chitosan oligosaccharide (COS) on angiogenic activities. Microvascular Research. 134:104114.

[5] Cheung, R. C., Ng, T. B., Wong, J. H., Chan, W. Y. 2015. Chitosan: An Update on Potential Biomedical and Pharmaceutical Applications. Marine Drugs. 13.

[6] Zargar, V., Asghari, M., Dashti, A. 2015. A Review on Chitin and Chitosan Polymers: Structure, Chemistry, Solubility, Derivatives, and Applications. ChemBioEng Reviews. 2:204-226.

[7] Behera, H. T., Mojumdar, A., Das, S. R., Jema, S., Ray, L. 2020. Production of N-acetyl chitooligosaccharide by novel Streptomyces chilikensis strain RC1830 and its evaluation for anti-radical, anti-inflammatory, anti-proliferative and cell migration potential. Bioresource Technology Reports. 11:100428.

[8] Hui, A., Yan, R., Wang, W., Wang, Q., Zhou, Y., Wang, A. 2020. Incorporation of quaternary ammonium chitooligosaccharides on $\mathrm{ZnO} /$ palygorskite nanocomposites for enhancing antibacterial activities. Carbohydrate Polymers. 247:116685.

[9] Kidibule, P. E., Santos-Moriano, P., Plou, F. J., Fernández-Lobato, M. 2020. Endo-chitinase Chit33 specificity on different chitinolytic materials allows the production of unexplored chitooligosaccharides with antioxidant activity. Biotechnol Rep (Amst). 27:e00500-e00500.

[10] Jafari, H., Bernaerts, K. V., Dodi, G., Shavandi, A. 2020. Chitooligosaccharides for wound healing biomaterials engineering. Materials Science and Engineering: C. 117:111266.

[11] Maillet, F., Poinsot, V., André, O., Puech-Pagès, V., Haouy, A., Gueunier, M., Cromer, L., Giraudet, D., Formey, D., Niebel, A., Martinez, E. A., Driguez, H., Bécard, G., Dénarié, J. 2011. Fungal lipochitooligosaccharide symbiotic signals in arbuscular mycorrhiza. Nature. 469:58-63.

[12] Halila, S., Samain, E., Vorgias, C. E., Armand, S. 2013. A straightforward access to TMGchitooligomycins and their evaluation as $\beta$ - $\mathrm{N}$-acetylhexosaminidase inhibitors. Carbohydrate Research. 368:52-56.

[13] Tømmeraas, K., Vårum, K. M., Christensen, B. E., Smidsrød, O. 2001. Preparation and characterisation of oligosaccharides produced by nitrous acid depolymerisation of chitosans. Carbohydrate Research. 333:137-144.

[14] Trombotto, S., Ladavière, C., Delolme, F., Domard, A. 2008. Chemical Preparation and Structural Characterization of a Homogeneous Series of Chitin/Chitosan Oligomers. Biomacromolecules. 9:1731-1738.

[15] Mao, S., Shuai, X., Unger, F., Simon, M., Bi, D., Kissel, T. 2004. The depolymerization of chitosan: effects on physicochemical and biological properties. International Journal of Pharmaceutics. 281:45-54.

[16] Xia, Z., Wu, S., Chen, J. 2013. Preparation of water soluble chitosan by hydrolysis using hydrogen peroxide. International Journal of Biological Macromolecules. 59:242-245.

[17] Olicón-Hernández, D. R., Vázquez-Landaverde, P. A., Cruz-Camarillo, R., Rojas-Avelizapa, L. I. 2017. Comparison of chito-oligosaccharide production from three different colloidal chitosans using the endochitonsanolytic system of Bacillus thuringiensis. Preparative Biochemistry \& Biotechnology. 47:116-122.

[18] Mutahir, Z., Mekasha, S., Loose, J. S. M., Abbas, F., Vaaje-Kolstad, G., Eijsink, V. G. H., Forsberg, Z. 2018. Characterization and synergistic action of a tetra-modular lytic polysaccharide monooxygenase from Bacillus cereus. FEBS Letters. 592:2562-2571.

[19] Mekasha, S., Tuveng, T. R., Askarian, F., Choudhary, S., Schmidt-Dannert, C., Niebisch, A., Modregger, J., Vaaje-Kolstad, G., Eijsink, V. G. H. 2020. A trimodular bacterial enzyme combining hydrolytic activity with oxidative glycosidic bond cleavage efficiently degrades chitin. Journal of Biological Chemistry. 295:9134-9146. 
[20] Wang, S.-M., Huang, Q.-Z., Wang, Q.-S. 2005. Study on the synergetic degradation of chitosan with ultraviolet light and hydrogen peroxide. Carbohydrate Research. 340:1143-1147.

[21] Ajavakom, A., Supsvetson, S., Somboot, A., Sukwattanasinitt, M. 2012. Products from microwave and ultrasonic wave assisted acid hydrolysis of chitin. Carbohydrate Polymers. 90:73-77.

[22] Dziril, M., Grib, H., Laribi-Habchi, H., Drouiche, N., Abdi, N., Lounici, H., Pauss, A., Mameri, N. 2015. Chitin oligomers and monomers production by coupling $\gamma$ radiation and enzymatic hydrolysis. Journal of Industrial and Engineering Chemistry. 26:396-401.

[23] Popa-Nita, S., Lucas, J.-M., Ladavière, C., David, L., Domard, A. 2009. Mechanisms Involved During the Ultrasonically Induced Depolymerization of Chitosan: Characterization and Control. Biomacromolecules. 10:1203-1211.

[24] dos Santos, A. L. W., El Gueddari, N. E., Trombotto, S., Moerschbacher, B. M. 2008. Partially Acetylated Chitosan Oligo- and Polymers Induce an Oxidative Burst in Suspension Cultured Cells of the Gymnosperm Araucaria angustifolia. Biomacromolecules. 9:3411-3415.

[25] Yang, Y., Yu, B. 2014. Recent advances in the synthesis of chitooligosaccharides and congeners. Tetrahedron. 70:1023-1046.

[26] Chambon, R., Despras, G., Brossay, A., Vauzeilles, B., Urban, D., Beau, J.-M., Armand, S., Cottaz, S., Fort, S. 2015. Efficient chemoenzymatic synthesis of lipo-chitin oligosaccharides as plant growth promoters. Green Chem. 17:3923-3930.

[27] Semeňuk, T., Krist, P., Pavličček, J., Bezouška, K., Kuzma, M., Novák, P., Křen, V. 2001. Synthesis of chitooligomer-based glycoconjugates and their binding to the rat natural killer cell activation receptor NKR-P1. Glycoconjugate Journal. 18:817-826.

[28] Le Dévédec, F., Bazinet, L., Furtos, A., Venne, K., Brunet, S., Mateescu, M. A. 2008. Separation of chitosan oligomers by immobilized metal affinity chromatography. Journal of Chromatography A. 1194:165-171.

[29] Xiong, C., Wu, H., Wei, P., Pan, M., Tuo, Y., Kusakabe, I., Du, Y. 2009. Potent angiogenic inhibition effects of deacetylated chitohexaose separated from chitooligosaccharides and its mechanism of action in vitro. Carbohydrate Research. 344:1975-1983.

[30] Fu, Q., Liang, T., Zhang, X., Du, Y., Guo, Z., Liang, X. 2010. Carbohydrate separation by hydrophilic interaction liquid chromatography on a 'click' maltose column. Carbohydrate Research. 345:2690-2697.

[31] Lowenthal, M. S., Kilpatrick, E. L., Phinney, K. W. 2015. Separation of monosaccharides hydrolyzed from glycoproteins without the need for derivatization. Analytical and Bioanalytical Chemistry. 407:5453-5462.

[32] Nagy, G., Peng, T., Pohl, N. L. B. 2017. Recent Liquid Chromatographic Approaches and Developments for the Separation and Purification of Carbohydrates. Anal Methods. 9:35793593.

[33] Buszewski, B., Noga, S. 2012. Hydrophilic interaction liquid chromatography (HILIC) -a powerful separation technique. Analytical and Bioanalytical Chemistry. 402:231-247.

[34] Fu, Q., Liang, T., Li, Z., Xu, X., Ke, Y., Jin, Y., Liang, X. 2013. Separation of carbohydrates using hydrophilic interaction liquid chromatography. Carbohydrate Research. 379:13-17.

[35] Honda, C., Katsuta, R., Yamada, M., Kojima, Y., Mamiya, A., Okada, N., Kawamura, T., Totsuka, A., Shindo, H., Hosaka, M., Nukada, T., Tokuoka, M. 2021. Novel glucoamylase-resistant glucooligosaccharides with adjacent $\alpha-1,6$ branches at the non-reducing end discovered in Japanese rice wine, sake. Carbohydrate Polymers. 251:116993.

[36] Hirata, N., Tamura, Y., Kasai, M., Yanagihara, Y., Noguchi, K. 1992. New, stable polyaminebonded polymer gel column. Journal of Chromatography A. 592:93-100.

[37] Yoon, J. H. 2005. Enzymatic synthesis of chitooligosaccharides in organic cosolvents. Enzyme and Microbial Technology. 37:663-668.

[38] Dong, H., Wang, Y., Zhao, L., Zhou, J., Xia, Q., Qiu, Y. 2015. Key Technologies of Enzymatic Preparation for DP 6-8 Chitooligosaccharides. Journal of Food Process Engineering. 38:336344. 
[39] Abla, M., Marmuse, L., Delolme, F., Vors, J.-P., Ladavière, C., Trombotto, S. 2013. Access to tetra-N-acetyl-chitopentaose by chemical $\mathrm{N}$-acetylation of glucosamine pentamer. Carbohydrate Polymers. 98:770-777.

[40] Greco, G., Letzel, T. 2013. Main Interactions and Influences of the Chromatographic Parameters in HILIC Separations. Journal of Chromatographic Science. 51:684-693.

[41] Jandera, P. 2011. Stationary and mobile phases in hydrophilic interaction chromatography: a review. Analytica Chimica Acta. 692:1-25.

[42] Delas, T., Mock-Joubert, M., Faivre, J., Hofmaier, M., Sandre, O., Dole, F., Chapel, J. P., Crépet, A., Trombotto, S., Delair, T., Schatz, C. 2019. Effects of Chain Length of Chitosan Oligosaccharides on Solution Properties and Complexation with siRNA. Polymers (Basel). 11:1236.

[43] Haebel, S., Bahrke, S., Peter, M. G. 2007. Quantitative Sequencing of Complex Mixtures of Heterochitooligosaccharides by vMALDI-Linear Ion Trap Mass Spectrometry. Anal. Chem. 79:5557-5566.

[44] Xu, L., Xia, D., Zhang, W., Guo, Z., Jin, G., Zhao, Y., Zhang, J. 2020. Large scale preparation of single chitin oligomers by the combination of homogeneous acid hydrolysis and reversed phase preparative chromatography. Carbohydrate Polymer Technologies and Applications. 1:100016.

[45] Lopes, J. F., Gaspar, E. M. S. M. 2008. Simultaneous chromatographic separation of enantiomers, anomers and structural isomers of some biologically relevant monosaccharides. Journal of Chromatography A. 1188:34-42.

[46] Fu, X., Cebo, M., Ikegami, T., Lämmerhofer, M. 2020. Separation of carbohydrate isomers and anomers on poly- $\mathrm{N}-(1 \mathrm{H}$-tetrazole-5-yl)-methacrylamide-bonded stationary phase by hydrophilic interaction chromatography as well as determination of anomer interconversion energy barriers. Journal of Chromatography A. 1620:460981.

[47] Bennett, R., Olesik, S. V. 2017. Gradient separation of oligosaccharides and suppressing anomeric mutarotation with enhanced-fluidity liquid hydrophilic interaction chromatography. Analytica Chimica Acta. 960:151-159.

[48] Bertuzzi, D. L., Becher, T. B., Capreti, N. M. R., Amorim, J., Jurberg, I. D., Megiatto Jr., J. D., Ornelas, C. 2018. General Protocol to Obtain D-Glucosamine from Biomass Residues: Shrimp Shells, Cicada Sloughs and Cockroaches. Global Challenges. 2:1800046.

[49] Pedrali, A., Bleve, M., Capra, P., Jonsson, T., Massolini, G., Perugini, P., Marrubini, G. 2015. Determination of $\mathrm{N}$-acetylglucosamine in cosmetic formulations and skin test samples by hydrophilic interaction liquid chromatography and UV detection. Journal of Pharmaceutical and Biomedical Analysis. 107:125-130.

[50] Harvey, D. J. 2011. Derivatization of carbohydrates for analysis by chromatography; electrophoresis and mass spectrometry. Journal of Chromatography B. 879:1196-1225.

[51] Ortner, F., Wiemeyer, H., Mazzotti, M. 2017. Interconversion and chromatographic separation of carbohydrate stereoisomers on polystyrene-divinylbenzene resins. Journal of Chromatography A. 1517:54-65.

[52] Bawazeer, S., Muhsen Ali, A., Alhawiti, A., Khalaf, A., Gibson, C., Tusiimire, J., Watson, D. G. 2017. A method for the analysis of sugars in biological systems using reductive amination in combination with hydrophilic interaction chromatography and high resolution mass spectrometry. Talanta. 166:75-80.

[53] Yan, J., Shi, S., Wang, H., Liu, R., Li, N., Chen, Y., Wang, S. 2016. Neutral monosaccharide composition analysis of plant-derived oligo- and polysaccharides by high performance liquid chromatography. Carbohydrate Polymers. 136:1273-1280.

[54] Kahle, V., Tesarik, K. 1980. Separation of saccharides and their anomers by high-performance liquid chromatography. Journal of Chromatography A. 191:121-128.

[55] Winkworth-Smith, C. G., MacNaughtan, W., Foster, T. J. 2016. Polysaccharide structures and interactions in a lithium chloride/urea/water solvent. Carbohydrate Polymers. 149:231-241.

[56] Guo, Y., Gaiki, S. 2005. Retention behavior of small polar compounds on polar stationary phases in hydrophilic interaction chromatography. Journal of Chromatography A. 1074:71-80. 
[57] Alpert, A. J. 2018. Effect of salts on retention in hydrophilic interaction chromatography. Journal of Chromatography A. 1538:45-53.

[58] Bicker, W., Wu, J., Yeman, H., Albert, K., Lindner, W. 2011. Retention and selectivity effects caused by bonding of a polar urea-type ligand to silica: A study on mixed-mode retention mechanisms and the pivotal role of solute-silanol interactions in the hydrophilic interaction chromatography elution mode. Journal of Chromatography A. 1218:882-895.

[59] Greco, G., Grosse, S., Letzel, T. 2012. Study of the retention behavior in zwitterionic hydrophilic interaction chromatography of isomeric hydroxy- and aminobenzoic acids. Journal of Chromatography A. 1235:60-67. 